\title{
ANALISIS MAKNA PEREMPUAN MASKULIN PADA FILM DISNEY BRAVE DAN MOANA
}

\author{
(Analisis Semiotika Christian Metz) \\ Luna Safitri Salsabil S.Ikom., M.Ikom \\ 1safitri@unis.ac.id \\ Program Studi Ilmu Komunikasi, Universitas Islam Syekh-Yusuf Tangerang.
}

\begin{abstract}
ABSTRAK
Perempuan dalam konstruksi sosial selalu digambarkan feminim, seperti pada film Disney. Namun film Disney saat ini di awal tahun 2010an, muncul pergeseran citra perempuan pada film animasi Disney khususnya film Brave dan Moana. Perempuan yang pada dahulu film Disney mencitrakan diposisi subordinasi, dependen, dan pasif kini berubah menjadi sosok yang mandiri, mampu memimpin, aktif dan tidak membutuhkan laki-laki. penelitian ini bertujuan melihat bagaimana media memaknai perempuan maskulin. Teori yang digunakan teori gender yang membahas bagaimana konstruksi dan memetakan gender. Penelitian ini bersifat kualitatif dengan semiotika Chris Mertz dalam mengintrepretasi data. Paradigma dalam penelitian ini adalah konstruktivis sehingga dapat menjelaskan bagaimana makna dibentuk. Hasil penelitian ini mengkonstruksikan perempuan menjadi tokoh utama dalam film brave (merida) dan moana (moana) yang mengarah pada karateristik maskulin. Seperti kuat, rasional, berani, mandiri, petarung, bernegosiasi. Saran dari penelitian ini diharapkan penelitian ini dapat menjelaskan media memaknai perempuan dan referensi mengenai studi gender

Kata kunci: Semiotika, Christian Metz, Charles Sanders Pierce, gender
\end{abstract}

\section{ABSTRACT}

Women in social construction are always portrayed as feminine, as in Disney films. However, the current Disney film in the early 2010s, there was a shift in the image of women in Disney animated films, especially Brave and Moana. Women who used to portray Disney's position as subordinate, dependent, and passive are now transformed into independent, able to lead, active and do not need men. This study aims to look at how the media interpret masculine women. The theory used is gender theory which discusses how to construct and map gender. This research is qualitative in nature with Chris Mertz's semiotics in interpreting the data. The paradigm in this research is constructivist so that it can explain how meaning is formed. The results of this study construct women as the main characters in the brave (merida) and moana (moana) films that lead to masculine characteristics. Like strong, rational, brave, independent, fighter, negotiate. Suggestions from this research are expected to be able to explain the media in understanding women and references about gender studies

Keywords: Semiotics, Christian Metz, Charles Sanders Pierce, gender 


\section{PENDAHULUAN}

Menurut Walter Lippman (2001:1) fungsi media sebagai "world outside and pictures in our heads". Proses pembentuk makna adalah hasil dari interpretasi media massa terhadap berbagai peristiwa sehingga dapat mengubah interpretasi orang tentang suatu realitas dan pola tindakan mereka. Realitas yang ada di media adalah realitas simbolik karena realitas yang sebenarnya tak dapat disentuh (untouchable). Kemampuan yang dimiliki media massa untuk menentukan realitas di benak khalayak, kemudian dimamfaatkan untuk kepentingan menciptakan opini publik (propaganda politik, promosi, public relations). Dari berbagai produk media massa seperti surat kabar, televisi, radio, dan film. Film menjadi produk media massa yang dapat mengubah konstruksi masyarakat dan media penyebaran ideologi

Menurut Chaniago (2017) film animasi, yang memiliki nilai pendidikan yang penting dengan mengajarkan normanorma sosial dan nilai-nilai tertentu, dan dengan mengirimkan pesan budaya yang beragam kepada anak-anak dari segala usia. Namun kini, anak-anak dibombardir oleh film-film animasi dengan pesan, gambar dan representasi yang beragam tentang gender, dan hal tersebut telah membangun dunia mimpi masa anak-anak yang tidak bersalah. Penampilan fisik tokoh di film animasi, peran sosial dan posisi mereka dalam masyarakat serta perilaku mereka secara tidak sadar membentuk pandangan anak-anak mengenai gender, dengan melihat peranan penting media dalam membentuk persepsi tentang laki-laki dan perempuan.

Sebagai salah satu pembuat film animasi pertama, Walt Disney telah menjadi bagian dari budaya Amerika bahkan dunia, dan memberikan pengaruh yang besar khususnya bagi anak-anak, selama bertahun-tahun. Tokoh animasi Disney, lagu, tema cerita dan pernak-pernik mereka adalah ikon budaya yang dihormati dan dipercayai oleh orang dewasa maupun anak-anak, baik yang tinggal di kota-kota besar maupun pedesaan, di seluruh dunia. Hal inilah yang menyebabkan peneliti tertarik untuk memilih film animasi produksi Walt Disney Company dalam penelitian ini. Ward (2002:120) berpendapat, "menjadi manusia, menurut Disney, adalah didefinisikan berdasarkan gender". Dalam kebanyakan film Disney: perempuan selalu berada pada posisi subordinasi, dependen, dan pasif, seperti dalam film Snow White, Cinderella, Sleeping Beauty, dan The Little Mermaid. Sedangkan peran laki-laki ditampilkan sebagai pahlawan 
dibanding tokoh perempuan (dengan presentase tokoh laki-laki 84\% dan tokoh perempuan 16\%). Vincent Faherty (2001) dalam penelitiannya tentang ras, gender, dan kerentanan sosial dalam film animasi Disney juga menyatakan bahwa, mayoritas dalam film animasi Disney, jumlah tokoh laki-laki lebih tinggi daripada jumlah tokoh perempuan (dengan presentase tokoh laki-laki sebesar $63 \%$ dan perempuan sebesar $28 \%$ ).

Namun pada perkembangan film Disney saat ini di awal tahun 2010an, muncul pergeseran citra perempuan pada film animasi Disney. Perempuan yang pada dahulu film Disney mencitrakan diposisi subordinasi, dependen, dan pasif kini berubah menjadi sosok yang mandiri, mampu memimpin, aktif dan tidak selalu membutuhkan laki-laki. Terlihat dari beberapa film animasi Disney tahun 2010an seperti brave dan moana. Perbedaan terreprentasi cukup signifikan, dari film animasi brave seorang putri (merida) yang akan di jodohkan oleh ibundanya (Ratu Elinor) agar posisi 4 klan bisa bersinergi dengan baik dan damai. Namun sosok merida mencoba melawan perjodohan dengan berbagai cara sampai mengubah ibu nya menjadi beruang.

Sedangkan dalam film animasi moana, perempuan digambarkan lebih maskulin dan mandiri. Dimana moana mencoba menyelamatkan desa tempat tinggalnya, mengarungi samudra luas untuk mengembalikan batu hati te fiti dengan bantuan maui seorang demi god. Dari film ini posisi laki-laki menjadi sub-ordinat tidak seperti dahulu laki-laki yang mendominasi dan menyelesaikan segala permasalah. Moana seorang perempuan mampu memimpin, berani, namun tetap memiliki ke khas-an perempuan yaitu sensitive. Namun dalam film animasi brave hingga moana kini makna cinta bergeser. Unsur dalam film merupakan sebuah konstruksi yang didasari oleh tanda-tanda. Hal ini dapat dibuktikan oleh van Zoest dalam Sobur yang mengatakan film dibangun dengan tanda semata-mata. Menurut Vera Nawiroh (2014:1) tanda yang dimaksudkan disini adalah tanda dalam semiotika. Ada banyak cara dalam memandang dan menganalisa tanda lewat aliran tokoh-tokoh semiotika, seperti Christian Mertz dan Charles Sanders Peirce. Metz (1991:74) berpendapat bahwa sinema yang terstruktur seperti bahasa. Mengadopsi model Saussure, Metz membuat perbedaan antara "langue" sistem bahasa, dan "bahasa". Bahasa struktur film kemudian dibagi menjadi delapan pengelompokan, yang termaktub dalam "The Large Syntagmatic Category" : Autonomous Shot, Paralel Syntagma, Bracket Syntagma, Descriptive Syntagma, 
Alternate Syntagma, Scene, Episodic

Sequence dan Ordinary Sequence.

Penelitan ini bertujuan mengkaji dan memaknai, bagaimanakah memakna Perempuan Maskulin Dalam Film Disney (Brave dan Moana).

\section{KAJIAN PUSTAKA}

\section{Gender dan Maskulinitas}

Gender merupakan kategori dasar dalam budaya, yakni sebagai proses dengan identifikasi tidak hanya orang, tetapi juga pembedaharaan kata, pola bicara, sikap dan perilaku, tujuan dan aktifitas seperti maskulinitas atau femininitas

Tabel 1.1 Pembedaan antara gender dan jenis kelamin

\begin{tabular}{|c|c|}
\hline Pemikiran & Pengertian \\
\hline $\begin{array}{l}\text { John M. } \\
\text { Echols } \\
\text { (dalan } \\
\text { Rachmawati } \\
\text { 2004) }\end{array}$ & $\begin{array}{l}\text { kata gender berasal dari } \\
\text { bahasa Inggris yang berarti } \\
\text { jenis kelamin. Secara umum, } \\
\text { pengertian Gender adalah } \\
\text { perbedaan yang tampak antara } \\
\text { laki-laki dan perempuan } \\
\text { apabila dilihat dari nilai dan } \\
\text { tingkah laku }\end{array}$ \\
\hline $\begin{array}{l}\text { Mansour } \\
\text { Fakih } \\
(20006)\end{array}$ & $\begin{array}{l}\text { gender merupakan suatu sifat } \\
\text { yang melekat pada kaum laki- } \\
\text { laki maupun perempuan yang } \\
\text { dikonstruksikan secara sosial } \\
\text { maupun kultural. Perubahan } \\
\text { cirri dan sifat-sifat yang } \\
\text { terjadi dari waktu ke waktu } \\
\text { dan dari tempat ke tempat } \\
\text { lainnya disebut konsep } \\
\text { gender. }\end{array}$ \\
\hline
\end{tabular}

\begin{tabular}{|l|l|}
\hline $\begin{array}{l}\text { HT.Wilson } \\
(1998)\end{array}$ & $\begin{array}{l}\text { yang memandang gender } \\
\text { sebagai "suatu dasar untuk } \\
\text { menentukan perbedaan } \\
\text { sumbangan laki-laki dan } \\
\text { perempuan pada kebudayaan } \\
\text { dan kehidupan kolektif yang } \\
\text { sebagai akibatnya mereka } \\
\text { menjadi laki-laki dan } \\
\text { perempuan. }\end{array}$ \\
\hline
\end{tabular}

Sumber : Sugiarti \& Handayani. 2002.

Konsep berpikir yang berkembang dalam masyarakat ketika mengkotak-kotakan gambaran pria maupun wanita secara ideal. Yang disebut stereotip gender. Stereotip terkadang bersifat positif dan negatif. Sebelum melangkah lebih jauh, ada baiknya mengenal lebih dulu perspektif mengenai seksualitas, sebagai berikut:

1. Perspektif ensensialis

2. Perpektif non-esensialis

Tabel 1.2 Pembedaan antara men (laki-laki) dengan women (perempuan)

\begin{tabular}{|l|l|}
\hline MEN are (should be) & $\begin{array}{l}\text { WOMEN are (should } \\
\text { be) }\end{array}$ \\
\hline Masculine & Feminine \\
\hline Dominant & Submissive \\
\hline Strong & Weak \\
\hline Aggressive & Passive \\
\hline Intelligent & Intuitive \\
\hline Rational & Emotional \\
\hline Active (do things) & $\begin{array}{l}\text { Communicative (talk } \\
\text { about things) }\end{array}$ \\
\hline MEN like & $\begin{array}{l}\text { WOMEN } \\
\text { like }\end{array}$ \\
\hline Cars/technology & Shopping/make up \\
\hline
\end{tabular}




\begin{tabular}{|l|l|}
\hline Getting drunk & $\begin{array}{l}\text { Social drinking with } \\
\text { friends }\end{array}$ \\
\hline $\begin{array}{l}\text { Casual sex with many } \\
\text { partner }\end{array}$ & Commited relationship \\
\hline
\end{tabular}

Tabel 1.3 Perbedaan maskulinitas dan feminitas

\begin{tabular}{|c|c|}
\hline Masculinity & Feminity \\
\hline $\begin{array}{l}\text { Strength }- \text { physical } \\
\text { and intellectual }\end{array}$ & $\begin{array}{l}\text { Beauty (within narrow } \\
\text { conventions) }\end{array}$ \\
\hline Power & $\begin{array}{ll}\text { Size/physique } & \text { (again, } \\
\text { within } & \text { narrow } \\
\text { conventions) } & \end{array}$ \\
\hline $\begin{array}{l}\text { Sexual attractiveness } \\
\text { (which may be based } \\
\text { on the above) }\end{array}$ & $\begin{array}{l}\text { Sexuality (as expressed by } \\
\text { the above) }\end{array}$ \\
\hline Physique & $\begin{array}{l}\text { Emotional (as opposed to } \\
\text { intellectual) dealings }\end{array}$ \\
\hline $\begin{array}{l}\text { Independence } \\
\text { thought, action) }\end{array} \quad$ (of & $\begin{array}{l}\text { Relationship (as opposed } \\
\text { to independence/freedom) }\end{array}$ \\
\hline $\begin{array}{l}\text { Being isolated as not } \\
\text { needing to rely on } \\
\text { others (the lone hero) }\end{array}$ & $\begin{array}{l}\text { Being part of a context } \\
\text { (family, } \\
\text { colleagues) }\end{array}$ \\
\hline
\end{tabular}

Sumber:www.mediaknowall.com/gender.html

Walaupun masih dinilai baru, namun kajian mengenai perempuan dan maskulinitasnya sudah banyak diangkat diberbagai pembahasan di beberapa kalangan masyarakat. Stereotip gender dianggap sebagai tuntutan sosial kultural. Konsep maskulinitas yang berlaku selama ini adalah konsep yang berdasarkan ideologi patriarki, mengutamakan dan menganggap pria sebagai makhluk superior. Pada dasarnya, tidak ada satupun kelas maupun kelompok yang dapat menentukan konstruksi maskulinitas sesungguhnya. Masing-masing pandangan maskulinitas dapat muncul ketika satu kekuasaan besar mendominasi dan memberikan asumsi. Asumsi-asumsi tersebut dengan cepat dapat berkembang di dalam kehidupan sosial masyarakat, kemudian dapat berbuah ideologi maskulinitas baru.

\section{METODOLOGI PENELITIAN}

Dalam penelitian ini paradigma yang digunakan adalah konstruktivis dan pendekatan kualitatif. Unit analisis, Sumber data menurut Nimmo (2004:81) dapat berupa pidato, dokumen tertulis, foto, surat kabar, acara televisi, dan gaya tubuh. Kemudian unit analisis merupakan bagian-bagian yang dipilih dari pesan keseluruhan. Unit analisis mana yang digunakan dalam penelitian bergantung dari Unit analisis pada penelitian ini adalah adegan-adegan yang terdapat pada film Disney Brave dan Moana. Teknik analisis data, metode analisa yang dipergunakan dalam penelitian ini adalah metode penelitian menggunakan semiotika Christian Metz. Teknik perfilman memiliki cara yang terpisah dalam arti makna terhadap satu potongan gambar (Stephen, 2014: 52).

\begin{tabular}{|l|l|l|}
\hline Keterangan & Penanda & Makna \\
\hline Shot Size & $\begin{array}{l}\text { Big Close Up } \\
\text {-XCU }\end{array}$ & $\begin{array}{l}\text { Emosi, Peristiwa } \\
\text { penting, } \\
\text { Dramatis }\end{array}$ \\
\hline
\end{tabular}




\begin{tabular}{|c|c|c|}
\hline & $\begin{array}{l}\text { Close Up } \\
(\mathrm{CU})-\mathrm{BCU}\end{array}$ & Keintiman \\
\hline & $\begin{array}{l}\text { Medium Shot } \\
\text { (MS) }\end{array}$ & $\begin{array}{l}\text { Hubungan } \\
\text { Personal dengan } \\
\text { subjek }\end{array}$ \\
\hline & $\begin{array}{l}\text { Long Shot } \\
(\mathrm{LS}) \text { - MLS }\end{array}$ & $\begin{array}{l}\text { Kontekstual dan } \\
\text { jarak public }\end{array}$ \\
\hline & $\begin{array}{l}\text { Full Shot } \\
\text { (FS) }- \text { XLS - } \\
\text { VLS }\end{array}$ & $\begin{array}{l}\text { Hubungan } \\
\text { Sosial }\end{array}$ \\
\hline \multirow[t]{3}{*}{$\begin{array}{l}\text { Sudut Ambil } \\
\text { Gambar }\end{array}$} & High Angle & $\begin{array}{l}\text { Dominasi, } \\
\text { Kekuasaan, } \\
\text { Kewenangan }\end{array}$ \\
\hline & Eye Angle & Kesetaraan \\
\hline & Low Angle & $\begin{array}{l}\text { Kelemahan, } \\
\text { infererioritas }\end{array}$ \\
\hline \multirow{7}{*}{$\begin{array}{l}\text { Jenis Lensa } \\
\text { Komposisi }\end{array}$} & Wide Angle & Dramatis \\
\hline & Normal & $\begin{array}{l}\text { Keseharian, } \\
\text { Normalitas }\end{array}$ \\
\hline & Tele & $\begin{array}{l}\text { Dramatis, } \\
\text { Keintiman, } \\
\text { Keserasian }\end{array}$ \\
\hline & Simestris & $\begin{array}{l}\text { Tenang, Stabil, } \\
\text { Religiusitas }\end{array}$ \\
\hline & Asimetri & $\begin{array}{l}\text { Keseharian, } \\
\text { Alamiah }\end{array}$ \\
\hline & Statis & $\begin{array}{l}\text { Ketiadaan } \\
\text { konflik }\end{array}$ \\
\hline & Dinamis & $\begin{array}{l}\text { Disorientasi, } \\
\text { gangguan }\end{array}$ \\
\hline \multirow[t]{3}{*}{ Fokus } & $\begin{array}{l}\text { Selective } \\
\text { Focus }\end{array}$ & $\begin{array}{l}\text { Menarik } \\
\text { perhatian }\end{array}$ \\
\hline & Soft Focus & $\begin{array}{l}\text { Romantika, } \\
\text { Nostalgia }\end{array}$ \\
\hline & Deep Focus & $\begin{array}{ll}\text { Semua } & \text { hal } \\
\text { penting } & \end{array}$ \\
\hline \multirow[t]{4}{*}{ Pencahayaan } & High Key & Kebahagian \\
\hline & Low Key & Kesedihan \\
\hline & $\begin{array}{l}\text { High } \\
\text { Contrast }\end{array}$ & Teatrikal \\
\hline & Low Contrast & Dramatis \\
\hline
\end{tabular}

\begin{tabular}{|l|l|l|}
\hline \multirow{4}{*}{$\begin{array}{l}\text { Kode } \\
\text { Sinematik }\end{array}$} & Zoom In & Observasi \\
\cline { 2 - 3 } & Zoom Out & Kontekstual \\
\cline { 2 - 3 } & $\begin{array}{l}\text { Pan (Left- } \\
\text { Right) }\end{array}$ & Mengikuti \\
\cline { 2 - 3 } & Till & Mengamati \\
\cline { 2 - 3 } & Fade In & Mulai atau Awal \\
\hline
\end{tabular}

Selain unsur terkecil diatas, hal yang tak kalah penting dalam memperhatikan sebuah video secara keseluruhan adalah urutan pengambilan gambar dari mulai yang terkecil hingga terbesar. Urutan tersebut dapat dilihat pada gambar di bawah ini:

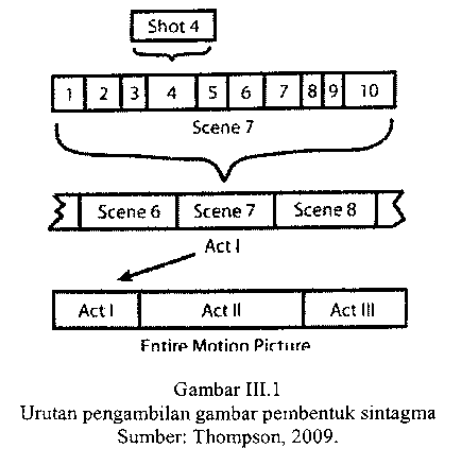

Tiap shot yang diambil dalam pembuatan film merupakan bagian yang diambil dalam sinema. Beberapa bidikan juga merupakan bagian dari adegan, yaitu yang berisikan tidak tematik yang lebih kecil untuk membuat urutan. Urutan dapat disebut juga sebagai tindakan untuk menjelaskan bagian-bagian dalam film sintagma (Thompson, 2009: 95). Dengan demikian, urutan ini memiliki fungsi yang sama dalam membentuk makna pada narasi yang lebih besar dari setiap sorotan gambarnya. 


\section{HASIL PENELITIAN DAN PEMBAHASAN}

\section{- Semiotika Christian Metz pada}

\section{film brave (Makna Hebat)}

\begin{tabular}{|l|}
\hline Sinematografi Semiotika Christian Metz \\
(Durasi scene 07:06 - 09:00) \\
\hline Shoot 1 \\
Shot pertama dimulai \\
dengan pengambilan gambar \\
secara long shot yang \\
menggambarkan merida
\end{tabular}

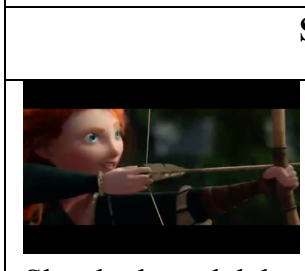

Shoot 2

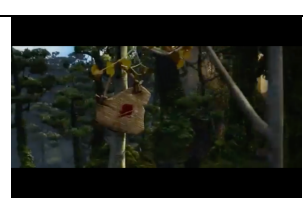

Shot kedua adalah adegan dimana merida dapat menggunakan alat panah dan anak panah tepat sasaran dengan angle close up, jenis lensa normal, komposisi adegan simetris, dan sudut ambil gambar eye level. Close up adalah teknik pengambilan gambar yang menunjukkan keintiman, bahwa merida memang dekat dengan kegiatan memanah. Komposisi simestris menunjukkan kestabilan, sedangkan sudut ambil gambar eye level menjelaskan kesetaraan yang bermakna bahwa merida terbiasa menggunakan alat panah.

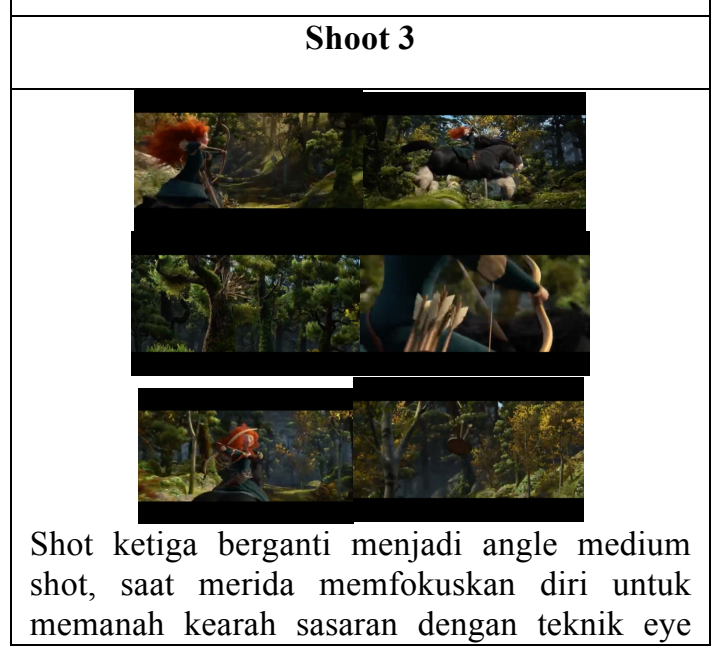

level dan wide angle sehingga terlihat lokasi bahwa merida sedang berada di hutan. Kemudian menggambarkan merida mampu menunggang sambil memanah dengan Teknik shot size long shot mengesankan sosok merida yang kuat. namun di sequence berikutnya pengambilan gambar secara close up di anak panah yang akan digunakan, merida dalam posisi memanah, dan akhirnya panahnya mengenai sasaran. Dua kali penggulangan adegan memberi penegasan pada karakter merida yang hebat dan kuat.

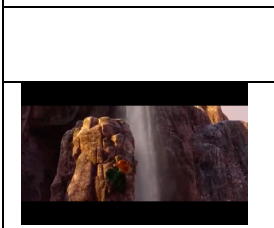

Shoot 4

$\begin{array}{llr} & \text { Shot } & \text { keempat, } \\ \text { merida } & \text { sedang } & \text { memanjat } \\ \text { tebing } & \text { sendirian } & \text { dengan } \\ \text { angle long shot, menjelaskan }\end{array}$
bahwa merida sedang melakukan kegiatan yang memacu adrenalin. Komposisi dalam scene yang simestris menggambarkan bahwa merida tenang dan terbiasa melakukannya. Sudut ambil gambar low angle untuk menjelaskan bahwa merida sedang di dalam situasi yang memungkinkan membahayakan dirinya.

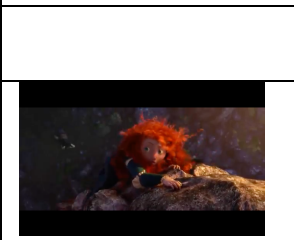

Shoot 5

sechang memanjat tebing dengan angle high sehingga background pada adegan terkesan merida sedang di kondisi menegangkan karena dia berada di tempat yang sangat tinggi. Ekspresi merida pun terlihat sedikit cemas terlihat dari fokus kamera selestive fokus sehingga posisi mimik muka merida terlihat lebih jelas dimana posisi alis terangkat.

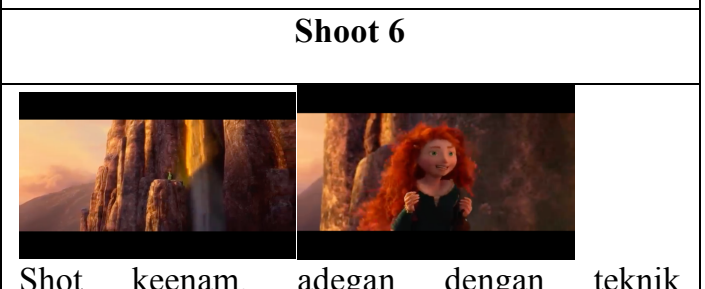
pengambilan gambar long shot dan closep up. Long shot untuk menjelaskan bahwa merida mampu memanjat tebing yang sangat tinggi, angle close up untuk menjelaskan ekspresinya yang senang dapat memanjat ke tebing itu. Maknanya dari adegan ini adalah menggambarkan bahwa merida adalah sosok yang aktif dan menyukai kegiatan diluar rumahnya.

Analisis tanda semiotika Christian Mertz yang muncul pada adegan ini 
adalah tanda Scene. Shot secara kronologis dan kontinyu menampilkan adegan-adegan spesifik. Mencari makna petanda dalam subtansi video yang tidak menampilkan banyak percakapan dari durasi scene 07:06 sampai dengan 09:00. Makna petanda dari adegan ini kemampuan merida pada shot 1 dan 3 dimana ia sebagai perempuan dapat menunggangi kuda. Makna petanda berikutnya pada adegan shot 2 dan 3 adalah merida sebagai perempuan dapat memanah. Dari kedua petanda ini memiliki makna maskulinitas dari segi sejarah berkuda adalah masuk kepada jenis olahraga yang diminati oleh kalangan bangsawan pada 5.000 tahun yang lampau sejak zaman kuno. Kuda dahalu juga sebagai modal transportasi sehingga tidak sembarang orang dapat menaikinya. Begitu pula memanah pada zaman dahulu merupakan olahraga bangsawan dan alat utama dalam mencari makan maupun perang bagi laki-laki. Namun pada film ini perempuan dapat menggunakan hal tersebut, menggambarkan bahwa perempuan saat ini hebat.

- Semiotika Christian Metz pada

film brave (Makna Rasional)

\begin{tabular}{|c|}
\hline Sinematografi Semiotika Christian Metz \\
(Durasi scene 11:50-12:59) \\
Shoot 1 \\
Shot pertama, shot size dimulai \\
dengan pengambilan gambar \\
secara long shot yang \\
menggambarkan Ratu Elinor memberikan kabar \\
bahwa para raja menerima dan mengajukan \\
pelamar untuk dijodohkan kepada merida. \\
Makna long shot dalam adegan ini adalah \\
menjelaskan dialog antara dua orang dengan
\end{tabular}

jarak posisi mereka dekat menjelaskan bahwa hubungan mereka dekat namun tidak intim.

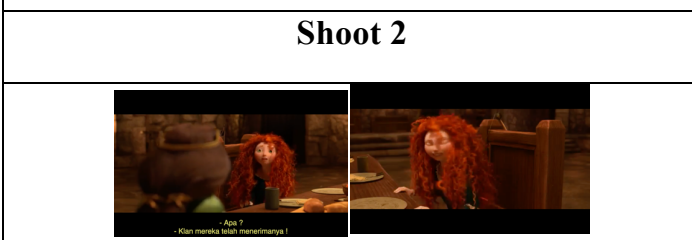

Shot kedua, shot size menjadi close up untuk menjelaskan respon merida mengenai perjodohan dirinya. Ekspresi yang ditampakan merida memberitahu bahwa ia tidak menyukai berita yang didapatnya.

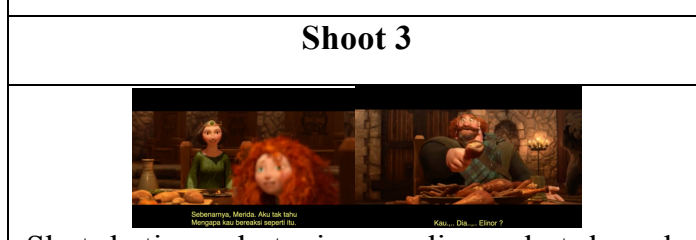

Shot ketiga, shot size medium shot kepada merida namun fokus kamera selective fokus kearah ibunya. Ekspresi merida meminta bantuan kepada ayahnya yaitu Fergus, namun Fergus yang tidak tau apa-apa meminta Elinor memberikan penjelasan mengenai perjodohan merida hal yang akan diselenggarakan.

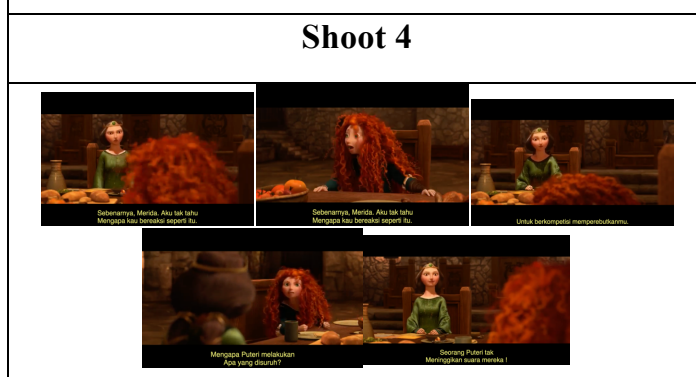

Shot keempat, shot size berganti kepada Merida dan Ratu Elinor yang saling tidak sependapat. Shot menjelaskan terjadi pertentangan diantara mereka.

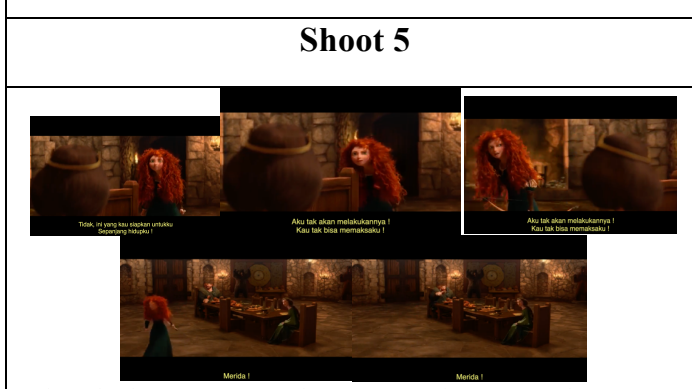

Shot kelima, Kemudian scene bergeser ke posisi merida yang sudah tidak kuat dengan perdebatan sehingga ia meninggal posisi duduknya berada. Merida menunjukkan kekecawaannya terhadap keputusan kedua orang tuanya yang berusaha menjodohkannya. Angle kamera kemudian menjadi long shot untuk menegaskan bahwa merida tegas dalam membela hak nya untuk menentang perjodohan. 
Analisis tanda semiotika Christian Mertz yang muncul pada adegan ini adalah tanda Scene. Shot secara kronologis dan kontinyu menampilkan adegan-adegan spesifik. Mencari makna petanda dalam subtansi video yang tidak menampilkan banyak percakapan dari durasi 11:50 sampai dengan 12:45. Makna petanda dari adegan ini dialog merida dengan ibunya pada shot 4 dimana ia menolak perjodohan. Makna petanda berikutnya pada adegan shot 5 adalah merida meninggalkan ruangan untuk mempertegas ketidak setujuannya terhadap keputusan orang tuanya. Merida adalah perempuan rational yang mengedepankan logikanya disbanding perasaanya

- Semiotika Christian Metz pada film brave (Makna Berani)

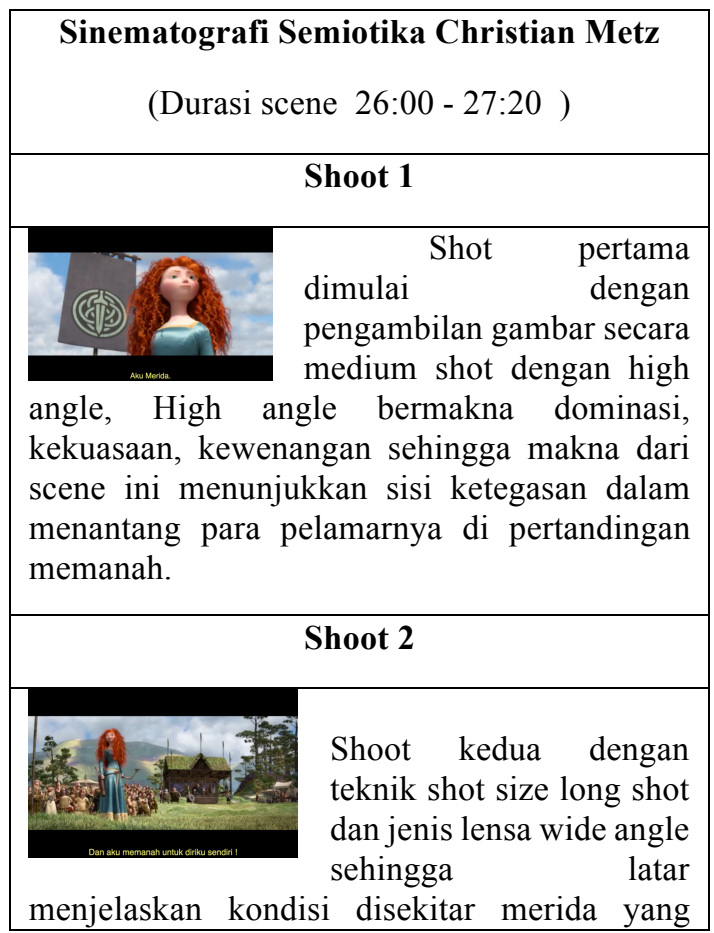

cukup ramai namun merida berdiri sendiri memperjuangkan kemauannya. Ekspresi merida yang mendongaknya kepalanya di hadapan orang-orang yang terdapat di sekitarnya bermakna bahwa ia berani melawan apa pun kondisinya

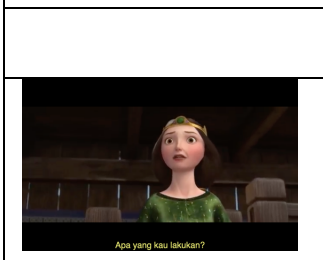

Shoot 3 bermakna keintiman sehingga tergambar bahwa ibunya tidak sukaan atas sikap yang ditunjukkan oleh merida. Ekspresi itu tersampaikan dari kedua alis yang mengangkat ke atas

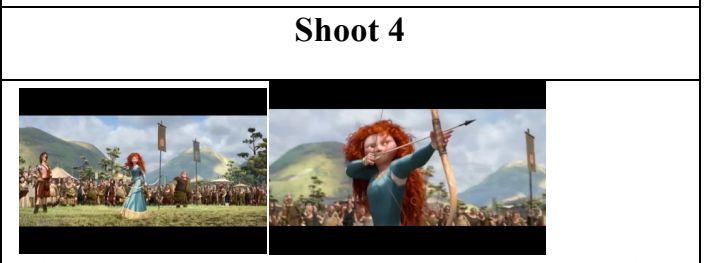

Shot keempat, shot size long shot menjelaskan kontekstual dan jarak public. Kontekstualnya adalah merida saat ini mencoba melawan penantangnya dihadap masyarat(orang-orang yang berada di belakangnya). Shot size kemduian menjadi medium shot merida bersiap untuk memanah dengan sudut ambil gambar eye level bermakna kesetaraan merida dengan para pelamarnya

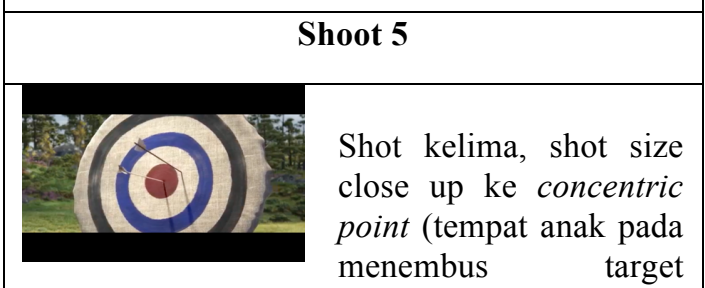
panah), shot ini menjelaskan bahwa merida dapat mengalahkan lawan pertamanya. Posisi anak panah merida tepat pada sasaran di tengah yang berwarna merah. Melampaui lawannya yang berada pada lingkaran putih yang terdekat dengan lingkaran merah di tengah

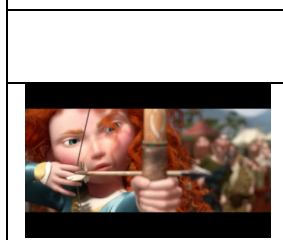

\section{Shoot 6}

Shot keenam, adegan angle close up dan fokus kamera selective focus pada merida. Fungsi close up untuk memperlihatkan ekspresi merida yang memfokuskan diri untuk mematahkan panahan pelamar yang kedua ditempat target (concentric point).

\section{Shoot 7}




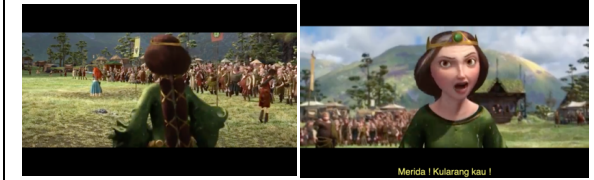

Shot ketujuh, kamera berubah ke long shot menggambarkan situasi disekitar merida yang sedang fokus dalam memanah di hadapan masyarakat(orang-orang). namun ibunya mencoba memberhentikan apa yang sedang dilakukan merida. Sequence berikutnya dengan shot size close up untuk menjelaskan ekspresi ibunya (Ratu Elinor) dalam menghadapi situasi dan perilaku merida. Ekspresi yang di keluarkan adalah ekspresi marah dengan garis alis yang tegas dengan penegasan muka yang membentak merida.

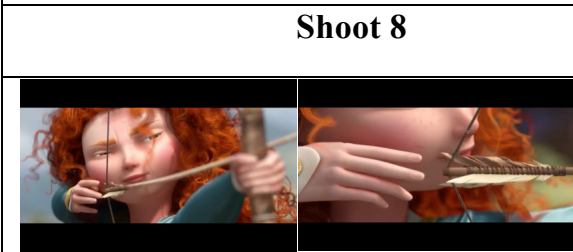

Shot kedelapan, shot size extreme close up dan fokus gambar selective focus pada bagian mata dan tangannya menjelaskan merida sedang sangat fokus untuk memanah ke target terakhirnya.

\section{Shoot 9}

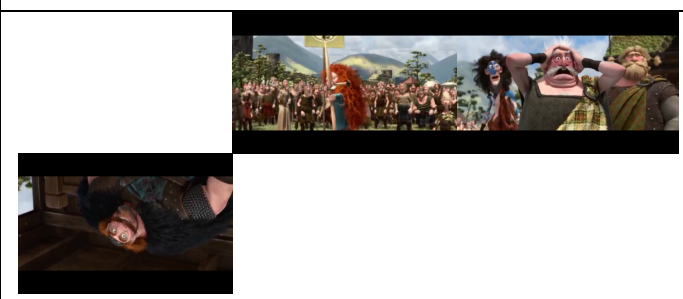

Shot kesembilan, shot size medium shoot menjelaskan posisi merida dan untuk menggambarkan respon orang-orang disekitarnya saat ia melepaskan panahannya. Shot size close up ke eskpresi ayahnya (Raja Fergus) dan raja-raja yang ada. Ekspresi yang di tampilkan ekspresi terkejut.

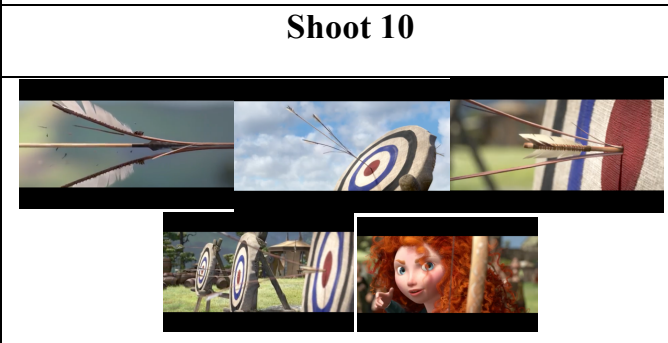

Shot kesepeluh, shot size close up ketika panahan meluncur dan tepat sasaran dengan angle extreme close up. Angle kamera ke medium shot untuk menjelaskan bahwa merida berhasil mematahkan panah setiap pelamarnya sehingga ia memenangkan pertandingan tersebut.

and

\section{Shoot 11} close up untuk menjelaskan ekspresi ibunya saat ini yang berada di sampingnya, merida dan ibunya saling memasang muka menantang. Hal ini menjelaskan ekspresi kekesalan masing-masing diantara mereka.

Analisis tanda semiotika Christian

Mertz yang muncul pada adegan ini adalah tanda Scene. Shot secara kronologis dan kontinyu menampilkan adegan-adegan spesifik. Mencari makna petanda dalam subtansi video yang tidak menampilkan banyak percakapan dari durasi 26:00 sampai dengan 27:20 . Makna petanda dari adegan shot 2 adalah merida menantang para pelamarnya melalui pertandingan panah . Makna petanda kedua pada adegan shot 4 dan shot 5 adalah merida dengan gagah membusurkan panahan kearah target. Makna petanda ketiga pada shot 11 menjelaskan ekspresi kekesalan merida dan ibunya di waktu yang bersamaan. Makna dari petanda yang adalah merida perempuan berani karena memperjuangkan haknya.

- Semiotika Christian Metz pada film moana (Makna Mandiri)

Sinematografi Semiotika Christian Metz 


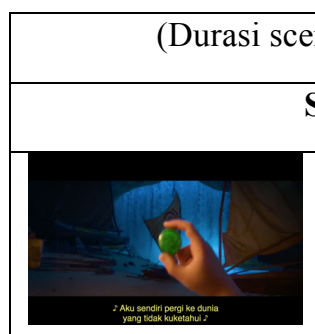

\section{Shoot 1}

Shot pertama, shot size long shot dan sudut jenis lensa yaitu wide lens. Hal ini menjelaskan mengenai situasi moana yang mencoba keluar dari desanya dengan perahunya. Ia mencoba berlayar dengan penggambaran air terjun yang menjadi gerbang antara daratan dan lautan

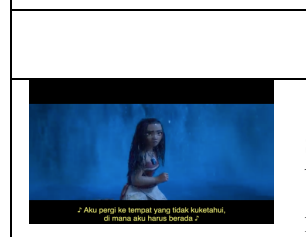

Shoot 2

Shot kedua, shot size medium shot moana berada di atas perahu melewati air terjun yang berada di belakangnya. Ekspresi yang terpancar oleh moana adalah gugup terlihat dari alis yang turun kebawah ini adalah ekspresi saat pertama kali berlayar.

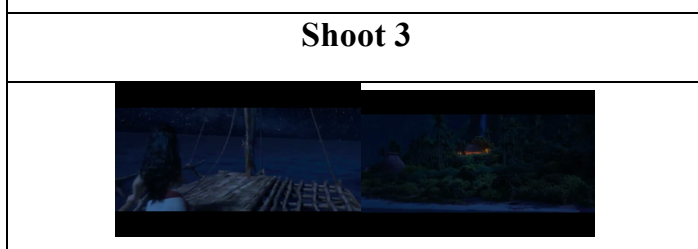

Shot ketiga, shot size medium shot yaitu moana sedang mendayung memandang ke depan untuk mengarungi samudra. Sequence berikutnya shot size long shot dan jenis lensa wide angle moana sedang beranjak mengarungi samudra dengan latar desanya.

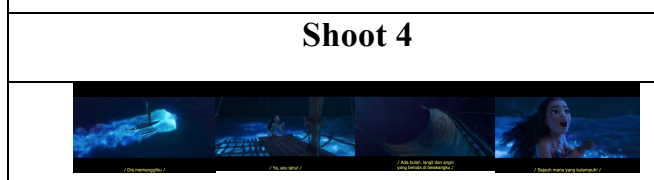

Shot keempat, shot size long shot menjelaskan moana yang berada di tengah lautan. Medium shot kearah moana yang sedang mendayung perahu, kemudian shot size menjadi kearah layer perahu dan close up ke ekspresi moana yang senang karena berlayar di samudra.

Analisis tanda semiotika Christian Mertz yang muncul pada adegan ini adalah tanda Episodic Squence. Episodic Sequence adalah shot yang dalam penyajiannya diskontinyu atau memiliki lompatan, namun cenderung konstan atau ajeg dan masih membicarakan hal/tujuan yang sama. Mencari makna petanda dalam subtansi video yang tidak menampilkan banyak percakapan dari durasi 31:09 sampai dengan 32:07. Makna petanda pertama dari adegan shot 2 adalah moana sendiri berusaha mendorong perahunya kearah laut, moana mencoba menjelajah. Makna petanda kedua dari shot 3 moana meninggalkan desa, menggambarkan untuk menjadi mandiri moana mencoba meninggalkan segala yang ia sayangi. Makna petanda ketiga adalah moana berlayar di lautan sendirian. Scene ini menjelaskan bahwa moana mencoba menjadi mandiri.

\section{- Semiotika Christian Metz pada}

film moana (Makna Petarung)

\begin{tabular}{|l|}
\hline $\begin{array}{l}\text { Sinematografi Semiotika Christian Metz } \\
\text { (Durasi scene } 35: 30 \text { - 38:00) }\end{array}$ \\
\hline $\begin{array}{l}\text { Shoot 1 } \\
\text { kamera long shot untuk menjelaskan posisi } \\
\text { moana dan maui yang hanya diperahu kecil } \\
\text { sedangkan berhadapan dengan perahu besar dari } \\
\text { perompak yaitu kakamoa. Dialog antara moana } \\
\text { dan maui untuk merebut kembali The Hearth of } \\
\text { Teh Fiti, namun maui tidak mau membantu } \\
\text { moana. }\end{array}$ \\
\hline \multicolumn{1}{c}{ Shoot 2 } \\
\hline $\begin{array}{l}\text { Shot kedua, Scene berikutnya menggambarkan } \\
\text { moana yang melompat kearah perahu kakamoa } \\
\text { untuk mencoba mengembalikan the hearth of } \\
\text { teh fiti sendirian. Maui yang melihat moana } \\
\text { melompat, terpaku dan membiarkan perahunya }\end{array}$ \\
\hline
\end{tabular}


menjauhi kapal kakamoa dengan angle kamera long shot.

\begin{tabular}{|c|}
\hline Shoot 3 \\
\hline \\
\hline 2 are
\end{tabular}

Shot ketiga, Angle kamera menjadi medium shot menjelaskan ekspresi kaget moana. Discene berikutnya pengambilan gambar long shot, menjelaskan bahwa moana sedang berhadapan dengan musuh yang jumlahnya cukup banyak.

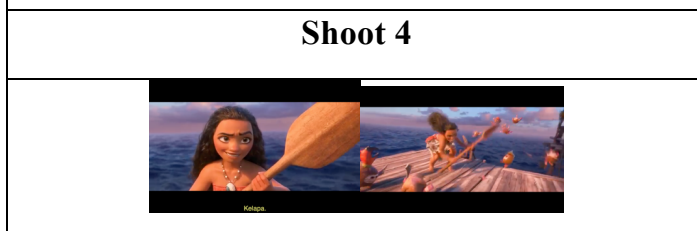

Shot keempat, Namun ekspresi moana menjadi senang diambil secara medium shot karena musuh yang di hadapinya adalah kelapa sehingga ia merasa bahwa itu bukan musuh yang berat. Scene berikutnya long shot menggambarkan moana sedang melawan kakamoa,

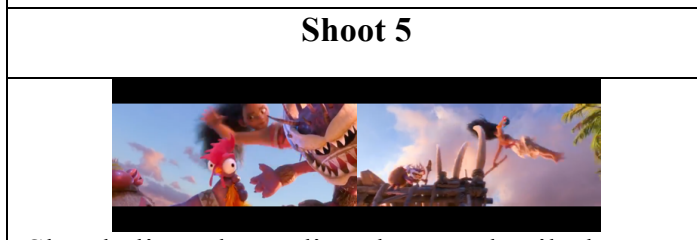

Shot kelima, kemudian dengan detail close up bahwa moana dapat mengambil the hearth of teh fiti.

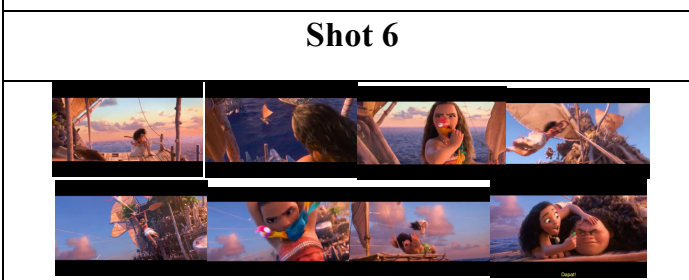

Shot keenam, Setelah itu adegan long shot menjelaskan bahwa moana sedang berusaha keluar dari kapal kakamoa karena sudah mendapatkan the hearth of teh fiti dan memberitahukan bahwa moana sedang berhadapan dengan resiko. Resiko yang dimaksud adalah moana sedang dalam posisi yang tinggis sehingga ia perlu mencari cara untuk keluar dengan cara terjun menggunakan tali kemudian bergelantungan. Makna dari adegan ini adalah bahwa moana berani.

Analisis tanda semiotika Christian

Mertz yang muncul pada adegan ini adalah tanda Episodic Squence. Episodic
Sequence adalah shot yang dalam penyajiannya diskontinyu atau memiliki lompatan, namun cenderung konstan atau ajeg dan masih membicarakan hal/tujuan yang sama. Mencari makna petanda dalam subtansi video yang menampilkan banyak percakapan dari durasi 49:30 sampai dengan 52:00. Makna petanda pertama dari adegan shot 1 adalah moana mencoba melawan kakamoa tanpa bantuan maui. Makna petanda kedua adalah moana mengambil the heart of teh fiti. Mana dari scene ini adalah moana seorang petarung.

- Semiotika Christian Metz pada film moana (Makna Negosiator)

\begin{tabular}{|c|}
\hline $\begin{array}{c}\text { Sinematografi Semiotika Christian Metz } \\
\text { (Durasi scene } 49: 30-52: 00 \text { ) }\end{array}$ \\
\hline Shoot 1 \\
\hline $\begin{array}{l}\text { Shot pertama, } \\
\text { shot size medium shot } \\
\text { menjelaskan moana dan } \\
\text { maui sedang berdialog } \\
\text { dengan fokus lensa selective focus kepada maui. } \\
\text { Selective focus menggambarkan moana sedang } \\
\text { mencoba menarik perhatian maui dengan cara } \\
\text { bernegosiasi. }\end{array}$ \\
\hline Shoot 2 \\
\hline $\begin{array}{l}\text { Shot kedua, shot size } \\
\text { medium shot dan fokus } \\
\text { selective focus pada ekspresi } \\
\text { moana. Ekspresi yang melihat }\end{array}$ \\
\hline Shoot 3 \\
\hline $\begin{array}{l}\text { Shot ketiga, shot } \\
\text { size menjadi close up kepada } \\
\text { maui, memperlihatkan } \\
\text { ekspresi maui yang sedang }\end{array}$ \\
\hline Shoot 4 \\
\hline
\end{tabular}




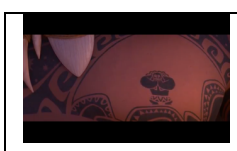

Shot keempat, shot size extreme close up menggambarkan tatoo maui yang memberi tahu bahwa maui takut dengan teh cala dengan menggigit jari dan pernah dikalahkan olehnya.

\begin{tabular}{|l|l|}
\hline \multicolumn{3}{|c|}{ Shoot 5} \\
$\begin{array}{l}\text { She kelima, shot } \\
\text { pada moana medium shot } \\
\text { adegan ini menjelaskan maui } \\
\text { sedang memberi tahu bahwa } \\
\text { tidak mungkin dapat }\end{array}$ \\
\hline
\end{tabular}

Shot keenam, shot size medium shot moana mencoba menyakinkan maui dengan tatapan tegasnya namun maui menolak dan bersikukuh ia hanya akan mengambil pancingnya. Moana kesal dengan keputusan maui, mencoba menjelaskan pada maui bahwa ia akan dianggap sebagai pahlawan jika mengembalikan the hearth of teh fiti.

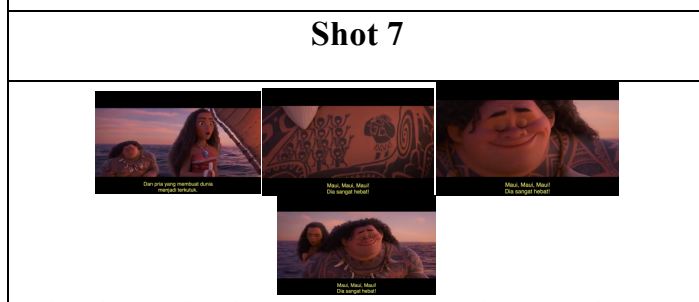

Shot ketujuh, shot size extreme close up di tatoo tubuh maui menggambarkan auntuisme dan sanjungan orang-orang jika maui mengembalikan the hearth of teh fiti. Adegan close up ke moana mengulang memberi tahukan maui bahwa dia akan dianggap pahlawan. Adegan long shot menjelaskan moana mencoba memanupulasi maui dengan cara mengulang membicarakan keinginannya dan mengiba pada maui.

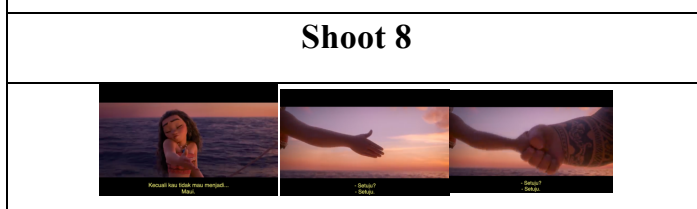

Shot kedelapan, angle kamera menjadi medium shot mengajak maui untuk menyepakati keinginan moana dengan menyodorkan tangannya. Adegan dengan close up moana dan maui akhirnya menyepakati untuk mengembalikan the heart of teh fiti.
Analisis Tanda semiotika Christian Mertz yang muncul pada adegan ini adalah tanda Scene. Shot secara kronologis dan kontinyu menampilkan adegan-adegan spesifik. Mencari makna petanda dalam subtansi video yang tidak menampilkan banyak percakapan dari durasi 49:30 sampai dengan 52:00. Makna petanda pertama dari adegan shot 1 adalah moana mencoba bernegosiasi dengan maui. Makna petanda kedua adalah maui menyepakati keingan moana. Makna petanda pada scene adalah moana mampu bernegosiasi sebagai perempuan.

- Makna perempuan maskulin dalam media

\begin{tabular}{|l|l|}
\hline \multicolumn{1}{|c|}{ Brave } & \multicolumn{1}{c|}{ Moana } \\
\hline Kuat & Mandiri \\
\hline Rasional & Petarung \\
\hline Berani & Bernegosiasi \\
\hline
\end{tabular}

Dundes dalam Ellington (2009:7) menyatakan bahwa analis media telah menegaskan bahwa film-film dari perusahaan Walt Disney Production ini secara spesifik memiliki kekuatan lebih besar dalam mendidik anak-anak mengenai peran gender lebih daripada sekolah-sekolah umum, institusi religius dan keluarga. Pernyataan ini pun didukung oleh penelitian Towbin, 
Haddock, Zimmerman, Lund dan Tanner dalam Ellington berdasarkan penelitian mereka, Rata-rata konsumsi anak-anak pada produk film Disney dua setengah jam sampai tiga jam bentuk media massa yang digunakan seperti konten film dalam televisi. Sehingga Disney sebagai perusahaan berperan penting dalam mengkonstruksi gender seperti maskulin dan feminim. Karateristik gender pada film Disney saat ini adalah maskulin seperti:

\section{Brave}

\section{Hebat}

Berkuda dan memanah memiliki nilanilai makna dan filosifi tersendiri yang menggambarkan maskulinitas. Makna maskulinitas dari segi sejarah berkuda adalah masuk kepada jenis olahraga yang diminati oleh kalangan bangsawan pada 5.000 tahun yang lampau sejak zaman kuno. Kuda dahalu juga sebagai modal transportasi sehingga tidak sembarang orang dapat menaikinya. Begitu pula memanah pada zaman dahulu merupakan olahraga bangsawan dan alat utama dalam mencari makan maupun perang bagi laki-laki. Namun pada film ini perempuan dapat menggunakan hal tersebut, menggambarkan bahwa perempuan saat ini hebat. (Farrell, 2015, h.41)

\section{Rasional}

Karakter perempuan maskulin dalam diri merida adalah perempuan rational yang mengedepankan logikanya dibanding perasaanya. Dalam kehidupan pribadi, kita sering merenungi tindakan-tindakan di masa yang telah lewat, mungkin dengan sedikit penyesalan karena merasa sudah bertindak bodoh atau tidak rasional. Selain itu, kita selalu menyempatkan waktu untuk berpikir ketika menghadapi persoalan yang penting, supaya solusi yang kita ambil tepat, masuk akal,atau rasional. Kemampuan manusia untuk berpikir dan bertindak secara rasional dipandang sebagai capaian tertinggi yang hanya mampu diraih oleh manusia, di antara semua mahluk hidup yang lain (Shafir \& LeBoeuf, 2002; Santos \& Rosati, 2015). 3. Berani

Karakter perempuan maskulin berani karena memperjuangkan haknya. Keberanian diartikan sebagai sifat yang berani menanggung resiko dalam pembuatan keputusan dengan cepat dan tepat waktu (frinaldi dan embi, 2011). Sifat keberanian seseorang tidak dimiliki sejak lahir tetapi sifat ini dapat dibentuk dengan membuat suasana yang kondusif sehingga dia 
merasa nyaman dan lebih percaya diri.

Dalam hal ini merida berani memperjuangkan nasibnya dan menanggung resiko atas sikapnya. Sikapnya cukup membahayakan kondisi dirinya sendiri namun ia tidak menghiraukannya. Moana

\section{Mandiri}

Sukadji (1986) mengemukakan arti kemandirian dengan kemampuan mengatur diri sendiri sesuai dengan hak dan kewajiban yang dimiliki, bertanggung jawab atas keputusan, tindakan, dan perasaan sendiri. Baik yang berhubungan dengan tindakan secara fisik ataupun perasaan secara psikis Selain itu juga mampu membuang perilaku yang menghindari kenyataan, sehingga seseorang yang tertatih untuk berdiri sendiri dapat mengatasi masalahnya sendiri. Kemandirian disebut sebagai kebebasan seseorang untuk menentukan sendiri masa depannya. Artinya orang tersebut membuat rencana untuk hidupnya berdasarkan keinginan dirinya sendiri. Kemandirian sebenarnya bukan suatu kesatuan dengan ketergantungan namun hal tersebut berkaitan satu sama lain.

2. Petarung
Moana adalah seorang petarung, menurut Buss dan Perry (1992) petarung adalah sikap yang memiliki perilaku agresif secara umum:

1. fisik, yaitu kecenderungan individu untuk melakukan serangan secara fisik sebagai ekspresi kemarahan

2. verbal, yaitu kecenderungan untuk menyerang orang lain atau memberi stimulus yang merugikan dan menyakitkan orang tersebut secara verbal yaitu melalui kata-kata atau melakukan penolakan

3. Kemarahan, yaitu representasi emosi atau afektif berupa dorongan fisiologis sebagai tahap persiapan agresi 4. Permusuhan, yaitu perasaan sakit hati dan merasakan ketidakadilan sebagai representasi dari proses berpikir atau kognitif

\section{Negosiator}

Istilah negosiasi berasal bahasa Inggris "negotiation", dalam pengertian secara umum negosiasi adalah proses tawar-menawar dengan cara berunding untuk mencapai kesepakatan kedua belah pihak (Ulinuha, 2013). Sedangkan Robbins (2003) mengartikan negosiasi adalah 
sebuah proses yang didalamnya dua pihak atau lebih bertukar barang dan jasa dan berupaya menyepakati tingkat kerjasama tersebut bagi mereka. Menurut Jackman (2005) negosiasi adalah sebuah proses yang terjadi antara dua pihak atau lebih yang pada mulanya memiliki pemikiran berbeda, hingga akhirnya mencapai kesepakatan.

\section{KESIMPULAN}

Perempuan maskulin pada film Disney adalah perempuan yang memiliki karakter dalam pandangan semiotika Christian Metz adalah kuat, rasional, berani, mandiri, petarung, bernegosiasi. . Namun pada film Disney brave perempuan ini justru menjauhi karakteristik feminim dan lebih condong kearah maskulin dengan jiwa suka berpetualang yang diwakilkan oleh scene. Mampu berspekulasi, perempuan pada "gender role" dikarakteristikan emosional, namun dengan mampu menggunakan senjata dan berspekulasi mengenai panah, perempuan ini mampu berspekulasi secara logika karena dapat memperhitungkan target dan tegas. Tegas karena dalam meluncurkan anak panah dibutuhkan fokus dan menghilangkan keraguan, sekali anak panah meluncur tidak ada penggulangan.

Sedangkan dalam film moana, perempuan maskulin diwakilkan melalui karakter ambisius. Ambisius karena moana akan melalukan segalanya untuk mengembalikan The Hearth Of Teh Fiti walaupun ia harus berkorban dengan meninggalkan orang-orang yang ia sayangi, melalui perjalanan sendirian hingga menghadapi ancaman untuk dirinya yang dahulu tidak pernah mengalami hal yang sulit. Oleh karena itu ia berkarter maskulin karena pada umumnya perempuan penurut, sehingga jika seseorang melarang atau mengaturnya perempuan akan mengikuti. Namun karakter moana jauh dari sikap penurut, ia pun cenderung mandiri sehingga tidak bergantung dengan siapa pun.

Moana mewakilkan sikap maskulin yaitu manipulatif, karena ia memainkan emosi pihak lawan bicaranya sehingga menuruti keinginannya. Dalam negosiasi umumnya jika perempuan berhadapan dengan laki-laki, perempuan akan menjadi sosok yang kalah dalam perundingan. Perempuan selalu dianggap pengambil keputusan yang buruk karena putusannya selalu dianggap tidak rasional, emosional, dan tidak berdasarkan data. Namun pada film ini saat moana berhadapan dengan lawan bicaranya yaitu maui, moana memainkan emosi maui dan melihat ego kelaki-lakian maui untuk mengikuti kemauan moana. Dari hal inilah karakter-karakter perempuan 
pada film Disney brave dan moana sangat mewakilkan kemaskulinitasan. Merupakan produk media untuk mengukuhkan nilai-nilai kesetaraan gender.

\section{DAFTAR PUSTAKA}

Alec Fisher. 2009. Berpikir Kritis Sebuah Pengantar. Terj. Benyamin Hadinata. Jakarta: Erlangga

Alex Sobur, Semiotika Komunikasi, Cetakan Keempat, PT. Remaja Rosdakarya, Bandung, 2009

Faherty, V. E. (August, 2001). Is the mouse sensitive? A study of race, gender, and social vulnerability in Disney Animated Films. Studies in Media \& Information Literacy Education, 1(3), 18. Diakses pada 25 April 2018 01.00, link: http://utpjournals.metapress.com/content/ 08r6082615151118/fulltext.pdf

Fakih, Mansour. 2008. Analisis Gender dan Transformasi Sosial. Yogyakarta: INSISTPress

Himawan Pratista, Memahami Film, Cetakan Kedua, PT. Homerian Pustaka, Yogyakarta, 2008
Marcel Danesi. 2010. Pengantar Memahami semiotika Media. Yogyakarta: Jalasutra

Panuti Sudjiman (ed), Serba-serbi semiotika, Gramedia Pustaka Utama, Jakarta, 1992

Wiryanto,(2000), Teori Komunikasi Massa, Jakarta,Gramedia Widiasarana Indonesia

Ward, A. (2002). Mouse mortality: The rhetoric of disney animated film. Texas: University of Texas Press.

Stephen W. Littlejohn dan Karen A. Foss, Teori Komunikasi Theory of human communication, Cetakan kesembilan (ed), 2011, Jakarta: Salemba Humanika,

Panuti Sudjiman (ed), Serba-serbi semiotika, Gramedia Pustaka Utama, Jakarta, 1992

Widyatama, Rendra. Bias Gender Dalam Iklan Televisi. Yogyakarta: Media Pressindo. 2006. 
Segall, Lynne. Chapter Four: Sexualities. Identity and Difference edited by Kathryn Woodard. 2002

http://www.mediated.co.uk/posted docu ments/MagazineAdverts.html diakses pada Senin 21 Januari 2019 pukul 02.00 WIB

Djajanegara, Soenarjati. 2000. Kritik Sastra Feminis: Sebuah Pengantar. Jakarta: Gramedia Pustaka Utama

Sugihastuti dan Suharto. 2010. Kritik

Sastra Feminis, Teori dan Aplikasinya.

Yogyakarta: Pustaka Pelajar

Sastryani, S, 2007. Glosarium, Seks dan Gender. Yogyakarta: Carasuati Books hal.65

Widianto, Agnes. 2005. Hukum Berkeadilan Gender. Jakarta: Kompas

Manuruung, Ria, dkk. 2002. Kekerasan terhadap Perempuan pada Masyarakat Multi Etnik. Yogyakarta: Pusat Studi Kependidikan dan Kebijakkan UGM Ford Foundation. 